\title{
Twists and Turns
}

\author{
Birendra Raj Joshi* \\ Department of Radiology and Imaging, Tribhuvan University Teaching Hospital, Nepal
}

*Corresponding author: Birendra Raj Joshi, Department of Radiology and Imaging, Tribhuvan University Teaching Hospital, Nepal

\section{ARTICLE INFO}

Received: December 30, 2019

Published:

\section{ABSTRACT}

Keywords: Ovary; Epididymis; Arteries; Diastolic Flow; Hyperemia; Epididymorchitis; Coagulopathy; Venous Obstruction

Citation: Birendra Raj Joshi. Twists and Turns. Biomed J Sci \& Tech Res 24(2)-2020. BJSTR. MS.ID.004036.

\section{Introduction}

Torsion of testis and ovary require prompt diagnosis. Ultrasound plays important role in this context. The normal spectral waveform of the testicular artery and artery supplying the epididymis is a low-resistance and high-flow pattern [1]. The cremasteric artery supplying the scrotal wall has high resistance, low-flow pattern. In $50 \%$ of normal male population, a transmediastinal arterial branch of testicular artery accompanied with a large vein is present to supply capsular arteries. Quantification of outflow is achieved by resistive index [RI]. It is PSV-EDV $\backslash$ PSV and is rarely less than 0.5 in normal testis of healthy volunteers. In testicular torsion arterial flow need not be absent. The spectral waveform is variable depending on severity and duration of torsion. Absence of a dicrotic notch resulting in a monophasic waveform, increased resistance to arterial flow with a decrease in diastolic flow velocities and reversal of diastolic flow or absence of arterial flow may be the findings in testicular torsion [2]. A variety of testicular disorders were analyzed by Dogra et al. [3]. They concluded that spectral waveform analysis is critical to diagnosing incomplete torsion when color and power Doppler examinations are indeterminate.

A paradoxical increase in intratesticular blood flow occurs with the in twisting of the spermatic cord in detorsion. There may be hyperemia in the paratesaticular region. In epididymitis the overall flow is increased. In severe epididymorchitis increased RI with reversed diastolic flow is present. Venous obstruction precedes arterial obstruction. Increased testicular RI with absent diastolic flow indicates severe venous occlusion. Venous infarction may be a com plication of severe epididymorchitis or coagulopathy. Acute onset of hydrocele mimics acute torsion. Increased intratesticular arterial resistance may result. A diminished RI is commonly seen in epididymorchitis. Decreased RI or increased velocity with the same RI is present in testicular tumours. Increased venous flow is painful testis is suggestive of orchitis. Multiple anecoeic, serpiginous, tubular structures of varying sizes are present in intra and extratesticular varicolcele. Venous flow pattern and characteristic venous spectral wavewform and increased velocities during valsalva maneuver are present. Characteristic arterialized venous spectral waveform is present in congenital or post-traumatic AVM adnexal torsion is fifth most common gynecological emergency condition. Ovarian torsion is caused by rotation of the ovary with the vascular pedicle on its axis resulting in arterial, venous or lymphatic obstruction. Twisted adnexal masses are often midline, positioned cranial to the uterine fundus. Appearance of a cystic, solid or complex mass with or without pelvic fluid, thickening of the wall, and cystic hemorrhage are helpful sonographic findings. Enlarged ovary with absent or markedly diminished ovarian blood flow is present. Venous thrombosis without arterial occlusion may occur. Twisted vascular pedicle was seen in $88 \%$ of cases by Lee et al.

The movement of the probe during the color Doppler study showed whirlpool sign. The whirlpool sign is seen as a hypoechoeic band representing the vessels wrapping around the central axis. The positive whirlpool sign in the twisted vascular pedicle is the most definitive sign of ovarian torsion. Absence of blood flow in 
the twisted pedicle and visualization of flow in the artery alone are predictive of non-viability of the ovary [4]. The cross section of a twisted pedicle can have an appearance of a target, a snail shell, and large echogenic or hypoechoiec mass without any obvious layers produced by twisted vessels. Lee et al reported $94 \%$ predictability of the viability of the ovary when arterial and venous flow was seen in the twisted pedicle. Hemorrhagic infarction and necrosis of adnexal structures was present [5]. The twisted vascular pedicle corresponds to the broad ligament, fallopian tube and adnexal and ovarian branches of the uterine artery and vein. False positive diagnosis is present in ovarian tumour associated salpingitis, endometriosis, or hemorrhagic cyst associated edema.

ISSN: 2574-1241

DOI: $10.26717 /$ BJSTR.2020.24.004036

Birendra Raj Joshi. Biomed J Sci \& Tech Res

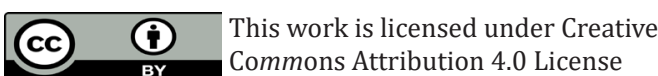

Submission Link: https://biomedres.us/submit-manuscript.php

\section{References}

1. Middleton WD, Thome DA, Nelson GL (1989) Color Doppler ultrasound of the normal testis. AJR Am j Roentogenol 152(2): 293-297.

2. Dogra VS, Sessions A, Mevosach RA Rubens DJ (2001) Reversal of diastolic plateau in partial testicular torsion. J Clin ultrasound 29(2): 105-108.

3. Dogra VS, Ruben DJ, Ronald HG, Bhatta S (2004) Torsion and beyond: new twists in spectral Doppler evaluation of the scrotum. J Ultrasound Med 23(8): 1077-1085.

4. Middleton WD, Bell MW (1993) Analysis of intratesticular arterial anatomy with emphasis on transmediastinal arteries. Radiology 189(1): 157-160.

5. Vijayaraghavan (2004) SB Sonographic whirlpool sign in ovarian torsion. J Ultrasound Med 23(12): 1643-1649.

$\begin{array}{ll}\text { BIOMEDICAL } & \text { Assets of Publishing with us } \\ \text { RESEARCHES } & \text { - Global archiving of articles } \\ & \text { - Immediate, unrestricted online access } \\ \end{array}$

